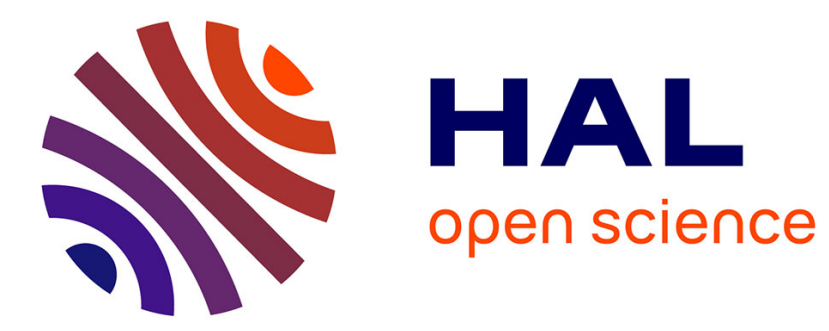

\title{
High-Frequency Surface Acoustic Wave Devices Based on Epitaxial Z-LiNbO3 Layers on Sapphire
}

\author{
Anthony Almirall, Stefania Oliveri, William Daniau, Samuel Margueron, \\ Thomas Baron, Pascal Boulet, Sylvain Ballandras, Stephane Chamaly, \\ Ausrine Bartasyte
}

\section{To cite this version:}

Anthony Almirall, Stefania Oliveri, William Daniau, Samuel Margueron, Thomas Baron, et al.. HighFrequency Surface Acoustic Wave Devices Based on Epitaxial Z-LiNbO3 Layers on Sapphire. Applied Physics Letters, 2019, 114, pp.162905 (6). 10.1063/1.5086757 . hal-02123712

\section{HAL Id: hal-02123712 \\ https://hal.univ-lorraine.fr/hal-02123712}

Submitted on 8 May 2019

HAL is a multi-disciplinary open access archive for the deposit and dissemination of scientific research documents, whether they are published or not. The documents may come from teaching and research institutions in France or abroad, or from public or private research centers.
L'archive ouverte pluridisciplinaire HAL, est destinée au dépôt et à la diffusion de documents scientifiques de niveau recherche, publiés ou non, émanant des établissements d'enseignement et de recherche français ou étrangers, des laboratoires publics ou privés. 


\section{High-Frequency Surface Acoustic Wave Devices Based on Epitaxial Z-LiNbO Layers on $_{3}$} Sapphire

Anthony Almirall, ${ }^{1,2}$ Stefania Oliveri, ${ }^{1}$ William Daniau, ${ }^{1}$ Samuel Margueron, ${ }^{1}$ Thomas Baron, ${ }^{1}$ Pascal Boulet, ${ }^{3}$ Sylvain Ballandras, ${ }^{4}$ Stephane Chamaly, ${ }^{2}$ and Ausrine Bartasyte ${ }^{1}$

${ }^{1}$ FEMTO-ST Institute, University of Bourgogne Franche-Comté, CNRS (UMR 6174), ENSMM, 26 rue de l'Epitaphe, 25030 Besançon, France

${ }^{2}$ Qualcomm France RFFE SARL, 1090, route des Crêtes, 06560 Sophia-Antipolis, France

${ }^{3}$ Jean Lamour Institute, CNRS (UMR 7198), Université de Lorraine, 2 allée André Guinier, 54011 Nancy, France

${ }^{4}$ frec|n|sys SAS, 18 Rue Alain Savary, 25000 Besançon, France

Correspondence: ausrine.bartasyte@femto-st.fr

\section{Abstract:}

Filter market demand pushes to the development of new piezoelectric materials to address modern telecommunication challenges. Composite wafers combining an epitaxial piezoelectric layer and a said high velocity and acoustic quality substrate is a promising way to answer that demand. However, the fabrication of high-quality $\mathrm{LiNbO}_{3}$ films with reproducible physical properties is complicated by the difficulty to control volatile $\mathrm{Li}_{2} \mathrm{O}$ incorporation into the film and to measure its composition. So far, large-scale production of films with physical properties suitable for the targeted applications is not available. In this paper, lithium niobate films with controlled nonstoichiometry were deposited by means of pulsed injection metalorganic vapor phase deposition. We have demonstrated a high acoustical performance for surface acoustic wave (SAW) devices operating in the frequency range from $3.7 \mathrm{GHz}$ up to $5.3 \mathrm{GHz}$ and based on grown epitaxial $\mathrm{Z}$-axis oriented $\mathrm{LiNbO}_{3}$ films on sapphire. An electromechanical coupling of $8 \%$ for the Rayleigh wave at $5.3 \mathrm{GHz}$ was demonstrated experimentally.

Keywords: SAW, $\mathrm{LiNbO}_{3}$ films, high frequency, CVD, waveguide

Radio-frequency (RF) filters are widely used in the field of telecommunications (smart phones, wifi, Bluetooth, automotive navigation, etc.). The next generation of radiofrequency (RF) telecom applications urgently requires filters operating at frequencies above $3 \mathrm{GHz}$, particularly operating in the C-Band (4-6 GHz). The conventional RF surface acoustic wave (SAW) filters are presently mainly fabricated on $\mathrm{LiNbO}_{3}(\mathrm{LN})$ and $\mathrm{LiTaO}_{3}$ (LT) single crystal substrates. The frequency of SAW devices is defined at first order by the period of interdigitated transducers (IDTs) and by the SAW phase velocity. The minimum period of IDTs, used in SAW industry mainstream, is $700 \mathrm{~nm}$ and the phase velocity of the available single crystal materials $\left(4200-4600 \mathrm{~m} \cdot \mathrm{s}^{-1}\right.$ and $3900-4200 \mathrm{~m} \cdot \mathrm{s}^{-1}$ for leaky shear waves in LN and LT, respectively), compatible with large - scale production, represent strong limits in that matter. So far, the frequency of RF SAW filters, produced at industrial scale, is limited to about $3.2 \mathrm{GHz}$. New low-loss materials with sufficiently high electro-mechanical coupling $\left(K_{s}^{2}\right)$ and high acoustic velocities 
are needed to achieve SAW filters at above-mentioned frequencies. A promising approach to satisfy this demand is to use guided acoustic waves in the piezoelectric layers.

Guided acoustic waves can be generated in piezoelectric layers on substrates presenting higher phase velocity than that of the piezoelectric film. ${ }^{1}$ As guided waves are dispersive by essence, the piezoelectric film thickness has to be adjusted in order to achieve specific frequencies, to optimize the electromechanical coupling, $K_{s}^{2}$, and to limit higher order mode contributions. ${ }^{2}$ The highest velocities can be attained at low $h / \lambda$ ratio (where $h$ is a piezoelectric film thickness and $\lambda$ is the wavelength imposed by IDTs) to the price of maximum dispersion effects. This guiding phenomenon, enabling a significant increase of the propagation velocity, was broadly studied in the literature. In the case of LN and LT submicron films, diamond and sapphire substrates were mainly considered for this purpose. ${ }^{3-6}$ Sapphire substrates are of particular interest due to their availability under the form of wafers with diameters in the range $100-200 \mathrm{~mm}$, and their very low acoustical absorption (very low equivalent viscous-acoustic losses). ${ }^{7}$ It was shown by means of simulations that acceleration of the acoustic waves could be achieved for different orientations of LN and LT films on different cuts of sapphire substrates. ${ }^{3,5,8}$ The increased propagation velocities were demonstrated experimentally on (YX)LN/R-sapphire, ${ }^{3,8}$ (YX)-LT/Rsapphire, ${ }^{8}$ and (ZX)-LN/C-sapphire ${ }^{3}$ heterostructures (where $\mathrm{C}$ stands for (ZX) orientation and $\mathrm{R}$ $\left(33^{\circ} \mathrm{YX}\right)$ orientation according IEEE Std-176 convention), ${ }^{9}$ as well. The phase velocity of Leaky wave in (ZX)-LN/C-Sapphire with $h / \lambda=0.035$ was $6480 \mathrm{~m} \cdot \mathrm{s}^{-1} .{ }^{8}$ However, the insertion losses of SAW devices based on LN/LT films, reported in literature, were $(8-50 \mathrm{~dB})$ incompatible with the industrial requirements $(<5 \mathrm{~dB}) .{ }^{10}$ It is worth noting that the studied devices operated at relatively low frequencies (several 100s of MHz) and that low losses are more difficult to achieve at frequencies above $2 \mathrm{GHz}$ as the wave propagation is more affected by the film roughness and the defects presents in the film. Moreover, the measured electromechanical coupling, $K_{\mathrm{s}}^{2}$, of SAW devices based on LN/LT films was very low and it was not higher than $1 \%$ although much higher values are expected theoretically. ${ }^{10}$ This indicates that further ameliorations of LN film quality and the development of high frequency SAW devices based on such films need to be considered. The unavailability of deposited LN films boosted the development of single-crystal films by polishing or crystal ion slicing (Smart-cut ${ }^{\mathrm{TM}}$ ) of industrially available LN wafers and wafer bonding techniques. ${ }^{11-13}$ Although, high acoustic velocities can be attained in these hybrid structures, their fabrication is time consuming and expensive. $\mathrm{ZnO}$ films on sapphire substrates are also considered for these purposes ${ }^{14}$ however, the electromechanical coupling of $\mathrm{ZnO}$ is limited.

LN phase exists over a large compositional range (from $46.5 \mathrm{~mol} \%$ to $50.5 \mathrm{~mol} \%$ of $\mathrm{Li}_{2} \mathrm{O}$ ) and $\mathrm{LN}$ physical and compositional properties are extremely dependent on the $\mathrm{Li}_{2} \mathrm{O}$ nonstoichiometry. ${ }^{10}$ Thus, the $\mathrm{Li}$ composition within the films has to be controlled with precision, around $0.2 \mathrm{~mol} \%$, in order to obtain reproducible physical properties ${ }^{15}$ (such as coercive field, acoustic velocity, $K_{s}^{2}$, etc.) and to meet the requirements on frequency and phase velocity control $( \pm 0.20 \%) .{ }^{16} \mathrm{Li}_{2} \mathrm{O}$ is also a volatile component at deposition temperatures of $\mathrm{LN}$ films (above $900 \mathrm{~K}$ ). The fabrication of high quality $\mathrm{LiNbO}_{3}$ films is complicated by the difficulty to control $\mathrm{Li}_{2} \mathrm{O}$ composition and consequently the composition and physical 
properties of the films. ${ }^{10}$ So far, large-scale production of films with physical properties suitable for the targeted applications is not available. The growth of LN films is studied since 70's but Li nonstoichiometry was not optimized and controlled. Li is a very light element and its composition is difficult to measure by direct analysis methods. ${ }^{10}$ In most of literature reports, authors claimed about single phase and even stoichiometric films using compositional analysis methods with precision not better than $\pm 10 \% .{ }^{10}$ Recently, the methods of compositional analysis were ameliorated considerably. ${ }^{17-19}$

In our work, LN films with controlled Li composition were deposited by means of pulsed injection metalorganic chemical vapor phase deposition. The propagation velocities and electromechanical coupling of SAW resonators, based on optimized Z-LN/C-Sapphire films, with operational frequencies in the range of 3.5 -11 GHz have been studied from both theoretical and experimental points of view.

Hereafter $(\mathrm{X}, \mathrm{Y}, \mathrm{Z})$ is an orthogonal reference system where $\mathrm{Z}$ is parallel to the $\mathrm{C}$-axis and $\mathrm{X}$ - to the A-axis, which is taken perpendicular to the mirror plane of the $3 \mathrm{~m}$ point group. High quality epitaxial Z-axis oriented LN films on C-sapphire substrates were deposited by pulsed-injection metalorganic chemical vapor deposition (PI MOCVD). More details about deposition conditions can be found in Ref. 17 and 20. The thickness of LN films was $158 \pm 6 \mathrm{~nm}$ (measured by means of spectroscopic ellipsometry). The root-mean-square film roughness was around $6.5 \mathrm{~nm}$ as determined by means of atomic force microscopy. Z(XY)Z Raman spectra were collected by using a S\&I MonoVista Raman spectrometer with excitation at $532 \mathrm{~nm}$. Raman modes were identified according to the assignment given in Ref. 21. The spectra were calibrated by measuring the spectra of Z-LN single crystal with congruent composition (48.34 mol\% of $\mathrm{Li}_{2} \mathrm{O}$ ) for an equivalent polarization configuration. Methods used to estimate the residual stresses and the $\mathrm{Li}_{2} \mathrm{O}$ nonstoichiometry by means of Raman spectroscopy analysis can be found in Ref. 17. The linear relationship between Li nonstoichiometry and Raman mode dampings were identified by Scott et al. ${ }^{22}$ The spectra were reduced by Bose distribution and fitted using independent damped harmonic oscillator spectral profiles and a linear baseline. The epitaxial quality (rocking curves and $\varphi$-scans) of the films was studied with a Bruker D8 Discover diffractometer with Co Ka radiation $(1.79026 \AA)$.

Two types of single-port resonators, able to excite SAW with wavelengths, $\lambda$, of $1 \mu \mathrm{m}$ (allowing to attain C-band frequencies) and $1.4 \mu \mathrm{m}$ (representing the main stream of SAW industry), were designed. The single-port resonators consisted of thirty aluminium IDT pairs and twenty aluminium electrode mirrors on each side of the transducer. These resonators were fabricated by using electron-beam lithography. The thickness of said Al electrodes, deposited by evaporation, was $50 \mathrm{~nm}$ and an additional $200 \mathrm{~nm} \mathrm{Al}$ layer was deposited by RF sputtering on the pads for reliable tip-probing measurements. In order to find out theoretically $K_{s}{ }^{2}$ and resonant frequencies of single-port SAW resonators, 1D and 2D simulations were performed by combined finite element $(\mathrm{FEM}) /$ boundary element analysis. ${ }^{23}$ Two propagation directions in $\mathrm{LN}$ films were considered: (ZXt) $/ 0^{\circ}$ (X-axis) and (ZXt) $/ 90^{\circ}$ (Y-axis). The elastic, piezoelectric and dielectric constants of congruent $\mathrm{LN}$ were taken from Kovacs et al. ${ }^{24}$ The resonators were characterized by admittance measurements, using a ROHDE \& SCHWARZ Vector Network 

frequency taken at maximum resistance, $f_{a}$ :

$K_{S}^{2}=\frac{\pi}{2} \frac{f_{r}}{f_{a}} \tan \frac{\pi}{2} \frac{f_{a}-f_{r}}{f_{a}}$.

According to XRD analysis, the LN films on C-Sapphire presented single orientation with (0001) planes parallel to the substrate surface. According to XRD analysis, the epitaxial relationship between sapphire substrate and LN film was $(0001)_{L N} \|(0001)_{\text {sapphire }}$ and $[11 \overline{2} 0]_{L N} \|[11 \overline{2} 0]_{\text {sapphire }}$. The grown films presented very high epitaxial quality: a full width at half maximum (FWHM) of the rocking curve of $0006 \mathrm{LN}$ reflection was of $0.255^{\circ}$ (Fig. 1 a inset) and the FWHM of peaks in $\varphi$-scan of $(01 \overline{1} 2)$ planes was $0.676^{\circ}$ (the resolution of diffractometer was of $0.220^{\circ}$ and $0.252^{\circ}$ for these measurement configurations, respectively). The Raman spectra of Z-LN film and congruent crystal, measured in $\mathrm{Z}(\mathrm{XY}) \mathrm{Z}$ polarization configuration, are compared in Fig. 1 a. The Raman spectrum of the LN film presented only $\mathrm{E}(\mathrm{TO})$ modes of $\mathrm{LN}$ phase as expected for this polarization configuration and Raman modes of sapphire substrate confirming a single phase composition of the film. The significant shifts of $\mathrm{E}(1 \mathrm{TO}), \mathrm{E}(3 \mathrm{TO}), \mathrm{E}(4 \mathrm{TO})$ and $\mathrm{E}(6 \mathrm{TO})$ mode frequencies with respect to those of single crystal are indicating a presence of tensile residual stresses. Residual stresses of $1.0 \pm 0.2 \mathrm{GPa}$ in the films were actually estimated from the shift of E(6TO) Raman mode. The damping parameters of Raman modes of the film were comparable to those of the single crystal, indicating that crystalline quality and nonstoichiometry of the films were similar to those of single crystal substrates. $\mathrm{Li}_{2} \mathrm{O}$ nonstoichiometry in the grown films was $48.75 \pm 0.2$ mol\% of $\mathrm{Li}_{2} \mathrm{O}$ (estimated from the damping parameter of $\mathrm{E}(1 \mathrm{TO})$ Raman mode by taking into account the stress effect on the damping of this mode ${ }^{17}$ ).

The $\mathrm{S}_{11}$ signal as a function of frequency of single-port SAW resonators with wavelength of $1.4 \mu \mathrm{m}$ on $158 \mathrm{~nm}$ thick (ZX)-LN/C-Sapphire film $(h / p=0.23$, where $p$ is the period of IDTs) are given in Fig. $1 \mathrm{~b}$, respectively. The resonators with propagation direction along $\mathrm{X}$ presented two resonances at 3.57 $\mathrm{GHz}$ and $3.77 \mathrm{GHz}$ with quality factor at resonance, $Q$, of 420 and 490 , respectively. A single resonance at $3.69 \mathrm{GHz}$ was observed in the case of the SAW propagation along Y-axis, with resonance quality factor of 700 and electromechanical coupling of $0.5 \%$. In the separate scan at higher frequencies up to $8 \mathrm{GHz}$, it was observed a minor resonance at $5.90 \mathrm{GHz}$.

The susceptance as a function of frequency in the range of $3 \mathrm{GHz}-12 \mathrm{GHz}$ of single-port SAW resonators with wavelength of $1 \mu \mathrm{m}$ on $158 \mathrm{~nm}$ thick (ZX)-LN/C-Sapphire films $(h / p=0.32)$ and propagation directions along $\mathrm{X}$-axis is presented in Fig. 2 a. In the case of both resonators, two major modes in the range of $4-6 \mathrm{GHz}$ and two minor modes at roughly $7 \mathrm{GHz}$ and $11 \mathrm{GHz}$ were observed. The acoustic waves of resonator 2 (R2) presented slightly lower frequencies $(4.72 \mathrm{GHz}, 5.43 \mathrm{GHz}, 6.82$ $\mathrm{GHz}$, and $10.92 \mathrm{GHz}$ ) than the waves of resonator $1(\mathrm{R} 1)(4.77 \mathrm{GHz}, 5.45 \mathrm{GHz}, 6.96 \mathrm{GHz}$, and 10.98 $\mathrm{GHz}$ ). These discrepancies in frequency $(<2 \%)$ can be attributed to the local variations of the 
thicknesses of piezoelectric and/or electrode films. The electromechanical couplings of the first and the second modes were around $2.7 \%$ and $8 \%$, respectively (Fig. 2 a). The first mode at $4.72-4.77 \mathrm{GHz}$ presented a resonance $Q$ factor of $220-300$ and the second one at $5.43-5.45 \mathrm{GHz}$ a $Q$ value in the range 30-40. The mode at $10.98 \mathrm{GHz}$ sounds like exhibiting high losses.

Theoretical simulations were done in order to estimate the theoretical frequencies/velocities and to identify the type of the contributing acoustic modes. The simulated velocities of the acoustic waves excited by using IDTs with wavelengths of $1 \mu \mathrm{m}$ and $1.4 \mu \mathrm{m}$ in $158 \mathrm{~nm}$ thick (ZXt) $/ 0^{\circ} \mathrm{LN}$ films on Csapphire and in bulk (ZXt) $/ 0^{\circ} \mathrm{LN}$ crystal are summarized in Table 1 . The simulations have indicated that four types of modes could be excited for the propagation direction along X-axis of Z-LN film on Csapphire by using IDTs with $\lambda=1 \mu \mathrm{m}$ : a pure shear mode - Love mode $(4.86 \mathrm{GHz})$, a Rayleigh wave (5.01 GHz), a Leaky Shear Surface Acoustic Wave (LSSAW, 7.59 GHz) and a Leaky Longitudinal mode (LLSAW, $11.17 \mathrm{GHz}$ ) with propagation almost collinear to the film surface (Fig. 2 b). LLSAW corresponds to high-velocity partially guided surface acoustic waves, referred also as a high-velocity (HV) SAW in literature. ${ }^{14}$ It is important to underline that the frequency of the Love wave was lower than that of the Rayleigh wave (Fig. 2 b) possibly due to mass loading. The mass loading on the Love wave is more significant than that on the Rayleigh wave. The Rayleigh and Love wave velocities are very close at $h / p=0.32$ and thus, these modes present slightly mixed character. This conclusion is supported by the observation of the corresponding electrode/surface motion reported in Fig. 2 b where one can see that the respective displacements seem to present slightly mixed character. In the case of resonators with $\lambda=1.4 \mu \mathrm{m}$, the frequency of Rayleigh wave $(3.63 \mathrm{GHz})$ was below the frequency of Love wave $(3.89 \mathrm{GHz})$ as expected for waves in the bulk (ZX)-LN crystals (see Table 1). LSSAW were not expected to be excited in bulk specimens. The Rayleigh wave propagates with phase velocity of $\approx$ $3750 \mathrm{~m} \cdot \mathrm{s}^{-1}$ along X-direction in bulk Z-LN, while its phase velocity was increased to $5010-5082 \mathrm{~m} \cdot \mathrm{s}^{-1}$ in Z-LN/C-sapphire heterostructure (for $\lambda=1.0-1.4 \mu \mathrm{m}$ ). The guiding effect of Love wave diminishes quickly with the increase of $h / p$ ratio: it was $5446 \mathrm{~m} \cdot \mathrm{s}^{-1}$ for $h / p=0.23$ and $4860 \mathrm{~m} \cdot \mathrm{s}^{-1}$ for $h / p=0.32$. The guiding effect is particularly strong on the phase velocity of the longitudinal wave: it increases up to $14322 \mathrm{~m} \cdot \mathrm{s}^{-1}$ for $\lambda=1.4 \mu \mathrm{m}$ as compared to its velocity of $11170 \mathrm{~m} \cdot \mathrm{s}^{-1}$ for $\lambda=1.0 \mu \mathrm{m}$.

In general, the measured frequencies and phase velocities are in relatively good agreement but experimentally measured values are slightly lower than the simulated ones. The change of $\mathrm{Li}$ nonstoichiometry by $1 \mathrm{~mol} \%$ could induce a change in phase velocity about around $1 \% .{ }^{15}$ Our thin films had very similar Li content (48.75 mol\%) as compared to the congruent crystals (48.34 mol\%). Thus, the deviation of experimentally measured frequencies by $2-10 \%$ cannot be attributed to the effect of Li nonstoichiometry. As indicated above, the imprecision in the thickness results in frequency deviations below $2 \%$. The film elastic and piezoelectric properties might be also highly affected by the presence of high tensile residual stresses (around $1 \mathrm{GPa}$ ), to be confirmed by further measurements.

All acoustic waves were accelerated by the guiding effect in (ZX)-LN film on C-sapphire substrates. However, the acceleration effect differs for different modes. The longitudinal modes are strongly guided 
in (ZX)-LN layers on sapphire substrates (experimentally measured phase velocity was $10920 \mathrm{~m} \cdot \mathrm{s}^{-1}$ ).

Unfortunately, the losses due to energy radiation in the substrate makes the application of this mode very limited. In the case of SAW propagation along Y-axis, the Rayleigh wave propagates with no beam steering and maximises its electromechanical coupling whereas Love wave contribution is not observed. However, it presents still moderate electromechanical coupling $(0.5 \%$ for $h / p=0.23)$ although the propagation velocity was significantly increased $\left(5166 \mathrm{~m} \cdot \mathrm{s}^{-1}\right)$. The simulated electromechanical coupling as a function of $h / p$ ratio for propagation directions along X-and Y-axis is given in Fig. $1 \mathrm{~b}$ (inset). In the case of $h / p=0.23$ and the propagation along $\mathrm{Y}$-axis, the $\mathrm{K}_{\mathrm{s}}{ }^{2}$ of $0.9 \%$ is expected theoretically in a good agreement with our experimental results. One can note, that the $\mathrm{K}_{\mathrm{s}}{ }^{2}$ decreases reducing $h / p$. Therefore, a trade-off needs to be done between phase velocities in excess of $5000 \mathrm{~m} \cdot \mathrm{s}^{-1}$, resonance quality factor higher than 500 and electromechanical coupling overpassing $1 \%$. The maximum electromechanical coupling of about $7.6 \%$ can be attained in the (ZX)-LN films on Sapphire by using $h / p=0.61-0.64$ in agreement with simulations, reported in literature. ${ }^{3}$ In order to attain $\mathrm{h} / \mathrm{p}=0.64$ with the standard period of $700 \mathrm{~nm}$, the thickness of $L N$ film should be around $450 \mathrm{~nm}$. Experimentally, the high-quality Z-LN films with this thickness is difficult to attain due to relaxation of high residual stresses by twins and cracks. ${ }^{18}$ Theoretically, the electromechanical coupling of $5.5 \%$ is expected at $h / p=0.32$ for propagation direction along X-axis (Fig. $1 \mathrm{~b}$ inset). However, $K_{s}^{2}$ values of $8 \%$ for the Rayleigh wave at $h / p=0.32$ was measured experimentally. Higher $K_{s}^{2}$ values can be partially related to the deviation from the congruent composition towards stoichiometric one and/or due to presence of very high tensile stresses $(1 \mathrm{GPa})$. Further investigations are needed to confirm these hypotheses.

To summarize, the guiding effect on the properties of different acoustic modes in (ZX)LN/C- films on Sapphire was studied experimentally and analyzed by theoretical simulations. We have demonstrated an high acoustical performance compatible with filter applications $\left(K_{s}^{2}\right.$ up to $8 \%$ ) for SAW devices operating in the frequency range from $3.7 \mathrm{GHz}$ up to $5.3 \mathrm{GHz}$ and based on grown epitaxial (ZX)-LN films on sapphire. High quality factors can be achieved by reducing $h / p$ ratio, which however implies electromechanical coupling reduction, and to take profit from low losses of the sapphire substrate. Extremely high velocities

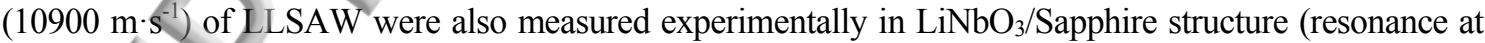
$10.9 \mathrm{GHz})$.

\section{Acknowledgments}

This research was funded by French RENATECH network, Bourgogne Franche-Comté region, EUR EIPHI program grant number ANR-17-EURE-0002, French National Research Agency funding ANR LiLit grant number ANR-16-CE24-0022-011 and ANR JCJC LiLa (ANR-12-JS04-0008-01). 
Table 1 Simulated (simul) and experimentally (exp) phase velocities $\left(\mathrm{m} \cdot \mathrm{s}^{-1}\right)$ of SAW with $\lambda=1.4 \mu \mathrm{m}$ and $\lambda=1.0 \mu \mathrm{m}$ excited in (ZXt) $/ 0^{\circ}(\mathrm{Z}-\mathrm{LN})$ crystal and $158 \mathrm{~nm}$ thick film on C-sapphire (C-sapph).

\begin{tabular}{lcccccc}
\hline \multirow{2}{*}{ Structure } & \multirow{2}{*}{ data } & \multirow{2}{*}{$h / p$} & Rayleigh & \multicolumn{3}{c}{ Acoustic wave } \\
& & Love & LSSAW & LLSAW \\
\hline \multirow{2}{*}{ Z-LN crystal } & simul & 0.23 & $\lambda=1.4 \mu \mathrm{m}$ & & & \\
Z-LN/C-sapph film & simul & 0.23 & 5082 & 5413 & & 4760 \\
& exp & 0.23 & 4970 & 5222 & 8456 & 14322 \\
Z-LN crystal & simul & 0.32 & $\lambda=1.0 \mu \mathrm{m}$ & & & Not studied \\
Z-LN/C-sapph film & simul & 0.32 & 5010 & 4030 & & 4750 \\
& $\exp$ & 0.32 & 5430 & 4760 & 7590 & 11170 \\
& & & & & & \\
\hline
\end{tabular}

Figure captions

Fig. 1 Z(XY)Z Raman spectra of Z-LN/ C-sapphire films and Z-LN crystal (a). The backgrounds were substracted and the amplitudes of $\mathrm{E}(1 \mathrm{TO})$ modes were normalized for the comparison purposes. The comparison of rocking curves (with nomalized intensity and $\Theta$ angle) of 0006 reflections of Z-LN and C-sapphire are given in the inset (a). $\mathrm{S}_{11}$ signal as a function of frequency of single-port SAW resonators with wavelength of $1.4 \mu \mathrm{m}$ and propagation directions along $\mathrm{X}$ - and $\mathrm{Y}$-axis (b). The simulated electromechanical coupling as a function of $\mathrm{h} / \mathrm{p}$ ratio for propagation directions along $\mathrm{X}$ - and $\mathrm{Y}$-axis is given in the inset (b).

Fig. 2 The experimentally measured susceptance as a function of frequency of two SAW resonators (R1 and R2) with propagation directions along X-axis (a). The zoom on the longitudinal mode is given in the inset (a). Simulated dependence of imaginary part of admittance of SAW with $\lambda=1.0 \mu \mathrm{m}$ excited in (ZXt) $/ 0^{\circ} 158 \mathrm{~nm}$ thick LN film on C-sapphire (b). The displacements of each wave are illustrated and the magnification ratio are indicated, as well. 
This manuscript was accepted by Appl. Phys. Lett. Click here to see the version of record.

\section{References}

1. H. Nakahata, A. Hachigo, K. Higaki, S. Fujii, S. Shikata, and Fujimori, IEEE Trans. Ultrason. Ferroelectr. Freq. Control 42, 362 (1995).

2. E.L. Adler, IEEE Trans. Ultrason. Ferroelectr. Freq. Control 37 (6), 485 (1990).

3. Y. Shibata, K. Kaya, K. Akashi, M. Kanai, T. Kawai, and S. Kawai, J. Appl. Phys. 77, 1498 (1995).

4. C. Zhou, Y. Yang, T. Ren, X. Wang, and S. Tian, Appl. Phys. Lett. 99, 022109 (2011).

5. M. Kadota, US 8304959 B2 (2012).

6. E. Dogheche, V. Sadaune, X. Lansiaux, D. Remiens, and T. Gryba, Appl. Phys. Lett. 81, 1329 (2002).

7. J.D. Klerk, Phys. Rev. 139 (5A), A1635 (1965).

8. Y. Shibata, N. Kuze, K. Kaya, M. Matsui, M. Kanai, and T. Kawai, Proc. IEEE Ultrason. Symp. 1, 148 (1996).

9. A. H. Meitzler, D. Berlincourt, G. A. Coquin, F. S. Welsh III, H. F. Tiersten, and A. W. Warner, IEEE Standard on Piezoelectricity, ANSI/IEEE Std Series 176-1978, Institute of Electrical and Electronics Engineers, New York, USA (1978).

10. A. Bartasyte, S.Margueron, T. Baron, S. Oliveri, and P. Boulet, Adv. Mater. Interfaces 4 (8), 1600998 (2017).

11. T. Pastureaud, M. Solal, B. Biasse, B. Aspar, J. Briot, W. Daniau, W. Steichen, R. Lardat, V. Laude, A. Laens, J. Friedt, and S. Ballandras, IEEE Trans. Ultrason. Ferroelectr. Freq. Control 54, 870 (2007).

12. M. Pijolat, S. Loubriat, S. Queste, D. Mercier, A. Reinhardt, E. Defaÿ, C. Deguet, L. Clavelier, H. Moriceau, M. Aïd, and S. Ballandras, Appl. Phys. Lett. 95, 182106 (2009).

13. A. Reinhardt, L. Benaissa, J.-B. David, N. Lamard, V. Kovacova, N. Boudou, and E. Defaÿ, Proc. - IEEE Ultrason. Symp. 773 (2014).

14. N.F. Naumenko and I.S. Didenko, Appl. Phys. Lett. 75 (19), 3029 (1999).

15. J. Kushibiki, I. Takanaga, S. Komatsuzaki, and T. Ujiie, J. Appl. Phys. 91 (10), 6341 (2002).

16. C. Lambert, D. Borrello, H. Choffat, P. Jacot, and E. Kuegler, 2nd International Symposium on Acoustic Wave Devices for Future Mobile Communication Systems, Chiba University, Japan, March 3-5, 2004.

17. A. Bartasyte, V. Plausinaitiene, A. Abrutis, T. Murauskas, P. Boulet, S. Margueron, J. Gleize, S. Robert, V. Kubilius, and Z. Saltyte, Appl. Phys. Lett. 101, 122902 (2012).

18. A. Bartasyte, V. Plausinaitiene, A. Abrutis, S. Stanionyte, S. Margueron, P. Boulet, T. Kobata, Y. Uesu, and J. Gleize, J. Phys.: Condens. Matter 25, 205901 (2013).

19. S. Margueron, A. Bartasyte, V. Plausinaitiene, A. Abrutis, P. Boulet, V. Kubilius, and Z. Saltyte, Proc. SPIE 862612 (2013)

20. A. Bartasyte, V. Plausinaitiene, A. Abrutis, S. Stanionyte, S. Margueron, V. Kubilius, P. Boulet, S. Huband, and P. A. Thomas, Mater. Chem. Phys. 149, 622 (2015).

21. S. Margueron, A. Bartasyte, A.M. Glazer, E. Simon, J. Hlinka, I. Gregora, and J. Gleize, J. Appl. Phys. 111, 104105 (2012).

22. B.A. Scott and G. Burns, J. Am. Ceram. Soc. 55 (5), 225 (1972).

23. A. Clairet, S. Oliveri, A. Almirall, T. Baron, W. Daniau, and A. Bartasyte, Proc. IEEE EFTF/IFC (2017).

24. G. Kovacs, M. Anhorn, H.E. Engan, G. Visintini, and C.C.W. Ruppel, Proc. IEEE Int. Ultrason. Symp. 435 (1990). 

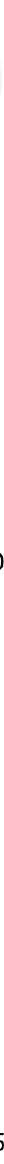
